\title{
Measurement of flow characteristics of a gear hydraulic pump by simulating the operating load of the tractor's hydraulic system
}

\author{
Lubomir Hujo ${ }^{1 *}$, Juraj Jablonickýl, Sylwester Borowski², Jerzy Kaszkowiak ${ }^{2}$, Matej \\ Michalides $^{l}$ \\ ${ }^{1}$ Slovak University of Agriculture in Nitra, Department of Transport and Handling, 94976 Nitra, \\ Slovakia \\ ${ }^{2}$ Faculty of Mechanical Engineering, UTP University of Science and Technology, al. Prof. S. \\ Kaliskiego 7, 85-796 Bydgoszcz, Poland
}

\begin{abstract}
The results of the work include research on changes in flow characteristics of gear hydraulic pump QHD 17 by simulating operating conditions on laboratory test equipment with assessment of influence of transmission-hydraulic fluid MOL Farm NH Ultra on technical and operational properties of hydraulic pump QHD 17. The laboratory test equipment makes it possible to repeatedly simulate real conditions under which the hydraulic system of the agricultural tractor operates, or to simulate the load with maximum pressure. By monitoring the change in the flow of the hydraulic pump at precisely determined intervals, which were 0 and 125 hours worked, the influence of the physical properties of the working fluid on the flow properties of the hydraulic pump was assessed and the measured data set was evaluated by mathematical-statistical analysis. Based on the physical properties of the tested MOL Farm NH Ultra fluid, which were determined from the samples taken at precisely determined intervals, no negative effect of the fluid itself as well as its properties on the flow efficiency of hydraulic pump QHD 17 was found.
\end{abstract}

\section{Introduction}

The identification of operating fluids is usually simple in practice thanks to the original packaging and it's marking (indications) if they are stored correctly. However, operating fluids are very often stored in containers that are usually unmarked or poorly stored, and their individual properties can be degraded [1]. The majority of the fixed displacement machines used for flow generation in fluid power systems are gear pumps [2]. The flow characteristics of the gear hydraulic pump QHD 17 when simulating the operating load of the tractor's hydraulic system are influenced by the state of the working fluid, which significantly contributes to the correct operation of the individual elements of the hydraulic circuit. In the case of the use of new working fluids in hydraulic circuits, it is important to have an overview of chemical and ecological properties of the fluids, as many materials used in hydraulic

*Corresponding author: lubomir.hujo@uniag.sk 
circuit elements are affected by working fluids, which affects the technical life of individual hydraulic circuit elements, resp. their components [3]. Machinery and equipment used in agriculture, according to [4] require continuous improvement in operating life and reliability. In order to optimize the testing time, accelerated tests of fluids are used, while the operational load is simulated in laboratory conditions. At the end of the test, we analyze the physicalchemical properties and the influence of the used working fluid on the technical condition of the hydraulic pump with a focus on monitoring changes in the flow characteristics of the hydraulic pump. With an experimental set of pressure measurements with numerical simulation for engines in laboratory conditions, we reduce the time required to perform operational measurements [5]. For this reason, the precise engineering production of individual elements of the hydraulic circuit is important, where it is important to monitor the accuracy of CNC machine tools using new methods and trends in product development and planning, where multilateral diagnostics of $\mathrm{CNC}$ machines is equally important $[6,7]$. The evaluation of hydraulic fluids due to the operational load with subsequent physical analysis was addressed by several authors in their work, as agricultural machinery is characterized by demanding operation in dusty and humid environments $[8,9]$. The results of the presented work can provide information suitable for manufacturers and users of both the gear hydraulic pump QHD 17 and transmission-hydraulic fluid MOL Farm NH Ultra.

\section{Material and Methods}

The basic prerequisite for the correct function and effective care of hydraulic fluids is a suitably chosen methodology for testing fluids with monitoring of the level of contamination of the working fluid. A comprehensive analysis of the effect of biological fluids and mixtures thereof has already been performed by author [10]. In order to optimize the testing time, accelerated tests of fluids are used, while in laboratory conditions we simulate the operating load. The measurement of hydraulic devices used in industry was also dealt by author [11]. At the end of the test, we analyse the physic-chemical properties and the influence of the used working fluid on the technical condition of the hydraulic pump, focusing on monitoring changes in the flow characteristics of the hydraulic pump. We know several different hydraulic pump tests that we use to obtain wear data and can be used to assess the properties of different fluids. In practice, there are mainly three basic methods of accelerated life tests of hydraulic elements:

- heavily contaminated fluid - it is assumed that the same hydraulic elements operated with a fluid with a higher content of impurities have a shorter service life than those that work with a fluid with a lower content of impurities,

- $\quad$ increased operating pressure,

- accelerating the work cycle.

Test equipment for monitoring the operating life of hydrostatic converters and drives in laboratory conditions is becoming increasingly important. This also implies a requirement for the development of such devices. Different types of loads must be used with these devices. To simulate the operating load of a gear hydraulic pump used in the tractor's hydraulic system when applying the tested hydraulic fluid, a laboratory test equipment was designed, which allows laboratory tests to be performed on the basis of signals recorded during operational tests. The course of the signal figure 1 which simulated real operating conditions during testing, is provided by means of an electrohydraulic proportional valve connected in a hydraulic circuit. 


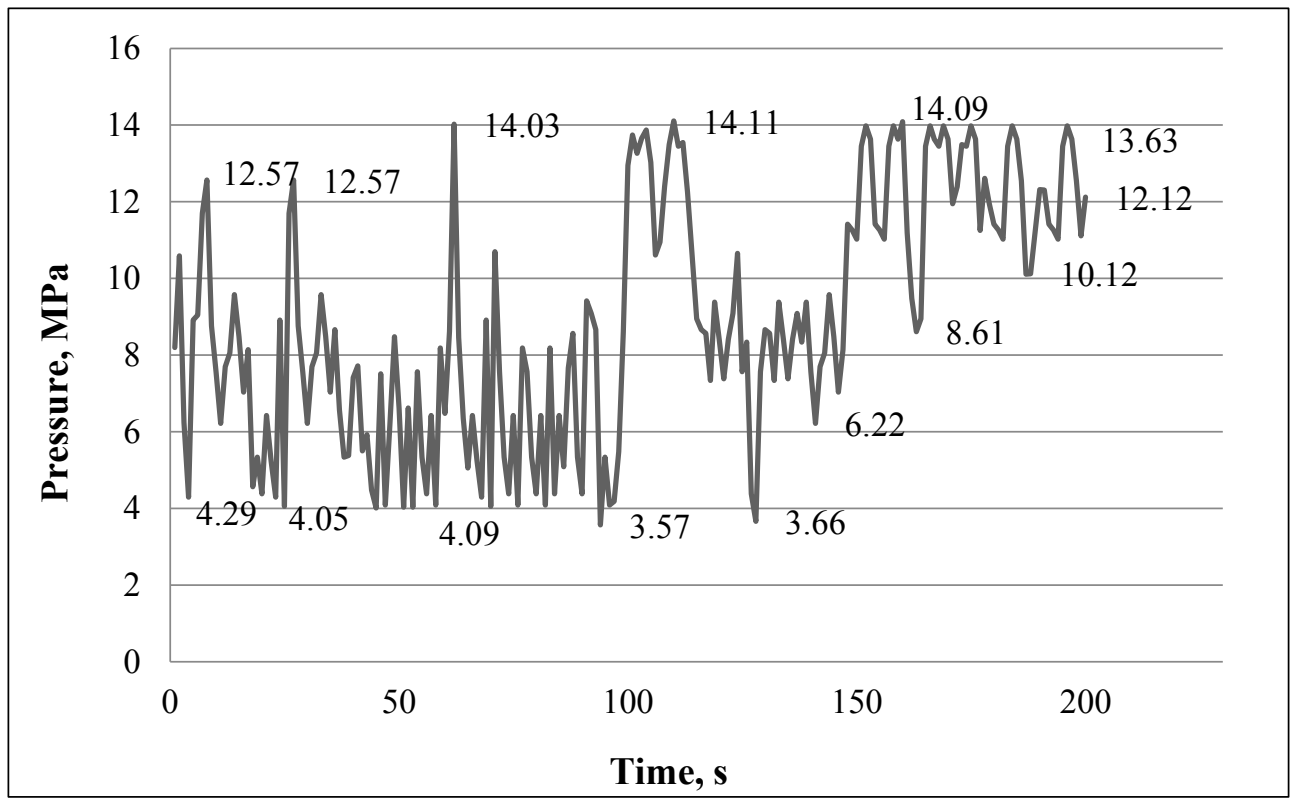

Fig. 1. The set of pressures in the hydraulic circuit of the tractor used in the simulation of the operation load.

The course of the laboratory test will be defined on the basis of operational measurements of the hydraulic system of the agricultural wheeled tractor ZETOR FORTERA 11441 and the laboratory test will take 500 hours at $1,500 \mathrm{rpm}$ and at intervals of 125 hours the flow characteristics of the hydraulic pump will be measured at a specified working fluid temperature of $40^{\circ} \mathrm{C}$. Ensuring of constant temperature $40^{\circ} \mathrm{C}$ will be achieve using a heater. When measuring the flow characteristics, we determine the operating pressure to the value 0 $\mathrm{MPa}$, i.e. without pressure load. We gradually increase the rotation of the hydraulic pump by $250 \mathrm{rpm}$ in the interval from $500 \mathrm{rpm}$ to $2,750 \mathrm{rpm}$. The following sensors were used to measure the characteristics of the transmission-hydraulic circuits (table 1):

- pressure sensor HDA 4748-H-0400-000,

- temperature sensor ETS 4148-H-006-000,

- flow sensor EVS 3108-H-0300-000.

Table 1. Basic parameters of used sensors

\begin{tabular}{|c|c|c|c|}
\hline Parameter & $\begin{array}{c}\text { EVS 3108-H-0300- } \\
\mathbf{0 0 0}\end{array}$ & $\begin{array}{c}\text { HAD 4748-H-0400- } \\
\mathbf{0 0 0}\end{array}$ & $\begin{array}{c}\text { ETS 4148-H-006- } \\
\text { 000 }\end{array}$ \\
\hline Measuring range & $15-300 \mathrm{dm} 3 / \mathrm{rpm}$ & $0-40 \mathrm{MPa}$ & -25 until $+100{ }^{\circ} \mathrm{C}$ \\
\hline Maximum pressure & $40 \mathrm{MPa}$ & $100 \mathrm{MPa}$ & $60 \mathrm{MPa}$ \\
\hline Inaccuracy & $\pm 0.8 \%$ & $\pm 0.25 \%$ & $\max 1{ }^{\circ} \mathrm{C}$ \\
\hline
\end{tabular}




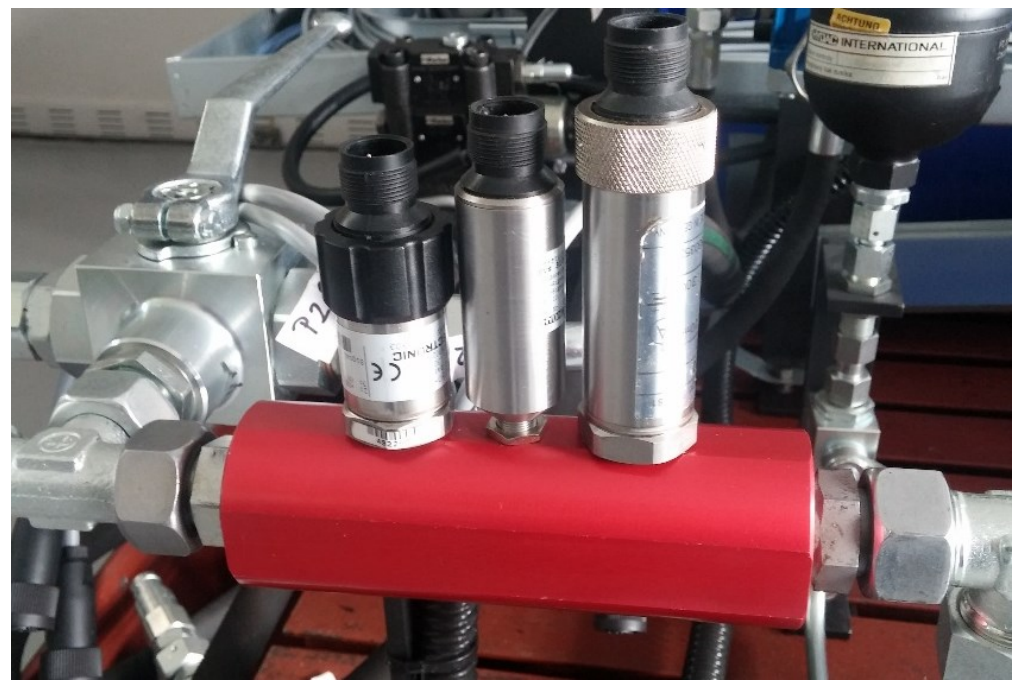

Fig. 2. Location of used sensors on the HYDAC connecting flange

Figure 2 shows the Hydac HMG 3010 recording unit, which is used to record the measured values of pressure, temperature and fluid flow, where it is possible to connect 10 sensors for sensing quantities and 32 measuring channels, which are shown individually on the display at a specified time. The device enables measurements with conversion coefficients with an accuracy of $1 \mathrm{~ms}$ and settings of the sampling frequency from $0.1 \mathrm{~ms}$ to 1 minute. The characteristics of the tested transmission-hydraulic fluid MOL Farm NH Ultra are used mainly in transmission-hydraulic systems of agricultural and forestry equipment, differentials, but also in the so-called wet brakes. The basic physical properties of the working fluid specified by the manufacturer are given in table 2 .

Table 2. Basic properties of transmission-hydraulic fluid Mol Farm NH Ultra

\begin{tabular}{|c|c|c|}
\hline Parameter & Unite & Value \\
\hline Density at $15^{\circ} \mathrm{C}$ & $\mathrm{kg} / \mathrm{m}^{3}$ & 875 \\
\hline Kinematic viscosity at $40^{\circ} \mathrm{C}$ & $\mathrm{mm}^{2} / \mathrm{s}$ & 64.2 \\
\hline Kinematic viscosity at $100^{\circ} \mathrm{C}$ & $\mathrm{mm}^{2} / \mathrm{s}$ & 10.9 \\
\hline Viscosity index & - & 162 \\
\hline Pour point & ${ }^{\circ} \mathrm{C}$ & -36 \\
\hline Flash point in an open container & ${ }^{\circ} \mathrm{C}$ & 210 \\
\hline
\end{tabular}

To evaluate the used hydraulic fluid in the hydraulic circuits of agricultural and forestry equipment, it is necessary to know the input parameters of the hydraulic system and the parameters of the hydraulic pump QHD 17, the technical parameters of which are given in table 3 . We will consider these parameters of the hydraulic pump as a reference, as they are set by the manufacturer. 
Table 3. Parameters of hydraulic pump QHD 17

\begin{tabular}{|c|c|c|c|c|}
\hline \multicolumn{2}{|c|}{ Parameter } & Mark & Unite & Value \\
\hline \multicolumn{2}{|c|}{ Real geometric volume } & $\mathrm{V}_{\mathrm{G}}$ & $\mathrm{dm}^{3}$ & $17.24 .10^{-3}$ \\
\hline \multirow{3}{*}{ Rotations } & rated & $\mathrm{n}_{\mathrm{n}}$ & rpm & 1,500 \\
\hline & minimum & $\mathrm{n}_{\min }$ & rpm & 350 \\
\hline & maximum & $\mathrm{n}_{\max }$ & $\mathrm{rpm}$ & 3,200 \\
\hline \multirow{2}{*}{ Inlet pressure } & minimum & $\mathrm{p}_{1 \text { min }}$ & MPa & -0.03 \\
\hline & maximum & $\mathrm{p}_{1 \text { max }}$ & $\mathrm{MPa}$ & 0.05 \\
\hline \multirow{3}{*}{ Outlet pressure } & $\begin{array}{l}\text { maximum } \\
\text { permanent }\end{array}$ & $\mathrm{p}_{2 \mathrm{n}}$ & $\mathrm{MPa}$ & 29 \\
\hline & maximum & $\mathrm{p}_{2 \max }$ & $\mathrm{MPa}$ & 31 \\
\hline & peak & $\mathrm{p}_{3}$ & $\mathrm{MPa}$ & 32 \\
\hline \multicolumn{2}{|c|}{ Rated output flow (min.) at $\mathrm{n}_{\mathrm{n}}$ and $\mathrm{p}_{2 \mathrm{n}}$} & $\mathrm{Q}_{\mathrm{n}}$ & $\mathrm{dm}^{3} / \mathrm{rpm}$ & 23.2 \\
\hline \multicolumn{2}{|c|}{ Maximum flow at $\mathrm{n}_{\max }$ and $\mathrm{p}_{2 \max }$} & $Q_{\max }$ & $\mathrm{dm}^{3} / \mathrm{rpm}$ & 54.3 \\
\hline \multicolumn{2}{|c|}{ Power - rated $(\max$.$) at n_{n}$ and $p_{2 n}$} & $P_{n}$ & $\mathrm{~kW}$ & 14.8 \\
\hline \multicolumn{2}{|c|}{ Maximum power at $\mathrm{n}_{\max }$ and $\mathrm{p}_{2 \max }$} & $P_{\max }$ & $\mathrm{kW}$ & 33.6 \\
\hline \multicolumn{2}{|l|}{ Mass } & $\mathrm{m}$ & $\mathrm{kg}$ & 10.9 \\
\hline
\end{tabular}

The following relation and statistical indicators were used to process the measured data:

\section{Hydrostatic transducer flow $Q$ :}

where:

$$
Q=V_{g} \cdot n \cdot \eta_{p r}, d m^{3} / r p m
$$

$V_{g}$ - geometric volume, $\mathrm{dm}^{3}$

$n-$ revolution, rpm

$\eta_{p r}-$ flow efficiency, -

\section{Arithmetic mean $\bar{x}$ :}

$$
\bar{x}=\frac{1}{N_{s}} \cdot \sum_{i=1}^{N_{s}} x_{i}
$$

where:

$N_{S}$ - the scope of the statistical order,

$x_{i}$ - the value of the variable $x_{i}$ unit,

Median $\operatorname{Med}(x)$ - the mean value of the statistical series, arranged according to the magnitude of the statistical values.

$\operatorname{Modus} \operatorname{Mod}(\mathbf{x})$ - the most common value of a statistical series, sorted by the size of the statistical values.

Minimum value $\boldsymbol{x}_{\min }$ - the smallest occurring value of the statistical series. 
Maximum value $\boldsymbol{x}_{\max }$ - the largest occurrence value of the statistical series.

Variance $\sigma^{2}$ :

$$
\sigma^{2}=\frac{1}{N} \cdot \sum_{i=1}^{N}\left(x_{i}-\bar{x}\right)^{2}
$$

where:

$\bar{x}$ - arithmetic mean of the statistical set,

Standard deviation $\sigma$ - positive square root of the variance.

$$
\sigma=\sqrt{\sigma^{2}}
$$

\section{Coefficient of variation $V_{k}$ :}

$$
V_{k}=\frac{\sigma}{\bar{x}} \cdot 100 \%
$$

Overall effectiveness $\eta_{c}$ : parameter of total losses in the circuit during power transfer on hydraulic pumps and hydraulic motors, which we get after multiplying the flow efficiency $\eta_{p r}$ (parameter for internal and external leakage flows in hydraulic pumps and hydraulic motors) with mechanical efficiency $\eta_{m}$ (parameter of losses caused by friction in hydraulic pump and hydraulic motors).

where:

$$
\eta_{c}=\eta_{p r} \cdot \eta_{m}
$$

$\eta_{c}$ - overall effectiveness, -

$\eta_{p r}-$ flow efficiency, -

$\eta_{m}-$ mechanical efficiency, -

\section{Flow efficiency $\eta_{p r}$ :}

where:

$$
\eta_{p r}=\frac{Q}{V_{g} \cdot n} \cdot 100 \%
$$

$\eta_{p r}$ - flow efficiency of the hydraulic pump, -

$Q$ - hydraulic pump flow, $\mathrm{dm}^{3} / \mathrm{rpm}$

$V_{g}$ - geometric volume of the hydraulic pump, $\mathrm{dm}^{3}$

$n-$ rotation of the hydraulic pump, rpm

Change in flow efficiency $\Delta \boldsymbol{\eta}_{p r}$ : the value expresses the wear of the hydraulic pump by a numerical value by which it is possible to compare the fluid.

$$
\Delta \eta_{p r}=\frac{\eta_{p r 0}-\eta_{p r m}}{\eta_{p r 0}} .100 \%
$$

where:

$\Delta \eta_{p \mathrm{r}}$ - change in flow efficiency, $\%$

$\eta_{\text {pro }}-$ flow efficiency at 0 hours (new hydraulic pump), -

$\eta_{p r m}-$ low efficiency after $\mathrm{m}$ hours worked, -

\section{Results}

The measurement of the flow characteristics of the QHD 17 hydraulic pump was performed during the simulation of the operating load after the interval of 125 hours worked, where the hydraulic pump rotation was gradually increased by $250 \mathrm{rpm}$ in the interval from $500 \mathrm{rpm}$ to 2,750 rpm. To measure the flow characteristics at specified pressures, we use the EVS 3100 sensor at a sampling frequency of $20 \mathrm{~ms}$, with a recording time $\mathrm{t}=10 \mathrm{~s}$. Table 4 shows the 
flow characteristics of the hydraulic pump at the beginning of the in-service test at 0 operating hours with a statistical evaluation as a function of the minimum rotation of $500 \mathrm{rpm}$ after $2,750 \mathrm{rpm}$.

Table 4. Basic statistical evaluation of flow characteristics of a hydraulic pump at 0 hours

\begin{tabular}{|c|c|c|c|c|c|c|c|c|c|}
\hline $\begin{array}{c}\text { Flo } \\
\text { w Q } \\
\text { at } \\
\text { rota } \\
\text { tion } \\
n \text {, } \\
\text { rpm }\end{array}$ & $\begin{array}{c}\text { Avera } \\
\text { ge, } \\
\overline{\mathbf{x}}\end{array}$ & $\begin{array}{c}\text { Median } \\
\text {, Me }\end{array}$ & $\begin{array}{l}\text { Modu } \\
\text { s, Mo }\end{array}$ & $\begin{array}{c}\text { Min. } \\
\text { value, } \\
\mathbf{x}_{\min }\end{array}$ & $\begin{array}{c}\text { Max. } \\
\text { value, } \\
\mathbf{x}_{\max }\end{array}$ & $\begin{array}{c}\text { Varianc } \\
\mathrm{e}, \sigma^{2}\end{array}$ & $\begin{array}{c}\text { Stand } \\
\text { ard } \\
\text { deviat } \\
\text { ion, } \\
\sigma\end{array}$ & $\begin{array}{c}\text { Coeff. } \\
\text { of } \\
\text { variatio } \\
\text { n, } \\
V_{\mathbf{k}}\end{array}$ & $\begin{array}{c}\text { Flo } \\
\text { w } \\
\text { effic } \\
\text { ienc } \\
y, \\
\%\end{array}$ \\
\hline 500 & 7.683 & 7.710 & 7.910 & 7.300 & 7.990 & 0.033 & 0.181 & 2.357 & $\begin{array}{c}88.3 \\
6 \\
\end{array}$ \\
\hline 750 & 12.043 & 12.060 & $\begin{array}{c}12.22 \\
0\end{array}$ & 11.570 & 12.420 & 0.044 & 0.209 & 1.739 & $\begin{array}{c}92.3 \\
3\end{array}$ \\
\hline $\begin{array}{c}100 \\
0\end{array}$ & 16.443 & 16.440 & $\begin{array}{c}16.12 \\
0\end{array}$ & 15.980 & 16.910 & 0.054 & 0.233 & 1.415 & $\begin{array}{c}94.5 \\
4\end{array}$ \\
\hline $\begin{array}{c}125 \\
0\end{array}$ & 20.851 & 20.850 & $\begin{array}{c}21.08 \\
0\end{array}$ & 20.310 & 21.340 & 0.064 & 0.253 & 1.212 & $\begin{array}{c}95.9 \\
2\end{array}$ \\
\hline $\begin{array}{c}150 \\
0\end{array}$ & 25.258 & 25.260 & $\begin{array}{c}25.59 \\
0\end{array}$ & 24.760 & 25.750 & 0.068 & 0.261 & 1.033 & $\begin{array}{c}96.8 \\
3\end{array}$ \\
\hline $\begin{array}{c}175 \\
0\end{array}$ & 29.662 & 29.670 & $\begin{array}{c}29.77 \\
0\end{array}$ & 29.130 & 30.200 & 0.072 & 0.269 & 0.905 & $\begin{array}{c}97.4 \\
7\end{array}$ \\
\hline $\begin{array}{c}200 \\
0\end{array}$ & 34.005 & 34.000 & $\begin{array}{c}33.68 \\
0\end{array}$ & 33.500 & 34.530 & 0.069 & 0.263 & 0.774 & $\begin{array}{c}97.7 \\
7\end{array}$ \\
\hline $\begin{array}{c}225 \\
0\end{array}$ & 38.358 & 38.350 & $\begin{array}{c}38.55 \\
0\end{array}$ & 37.830 & 38.910 & 0.069 & 0.263 & 0.685 & $\begin{array}{c}98.0 \\
3\end{array}$ \\
\hline $\begin{array}{c}250 \\
0\end{array}$ & 42.681 & 42.680 & $\begin{array}{c}42.48 \\
0\end{array}$ & 42.160 & 43.260 & 0.067 & 0.258 & 0.604 & $\begin{array}{c}98.1 \\
7\end{array}$ \\
\hline $\begin{array}{c}275 \\
0\end{array}$ & 46.983 & 46.990 & $\begin{array}{c}47.09 \\
0\end{array}$ & 46.460 & 47.550 & 0.059 & 0.243 & 0.517 & $\begin{array}{c}98.2 \\
4\end{array}$ \\
\hline
\end{tabular}

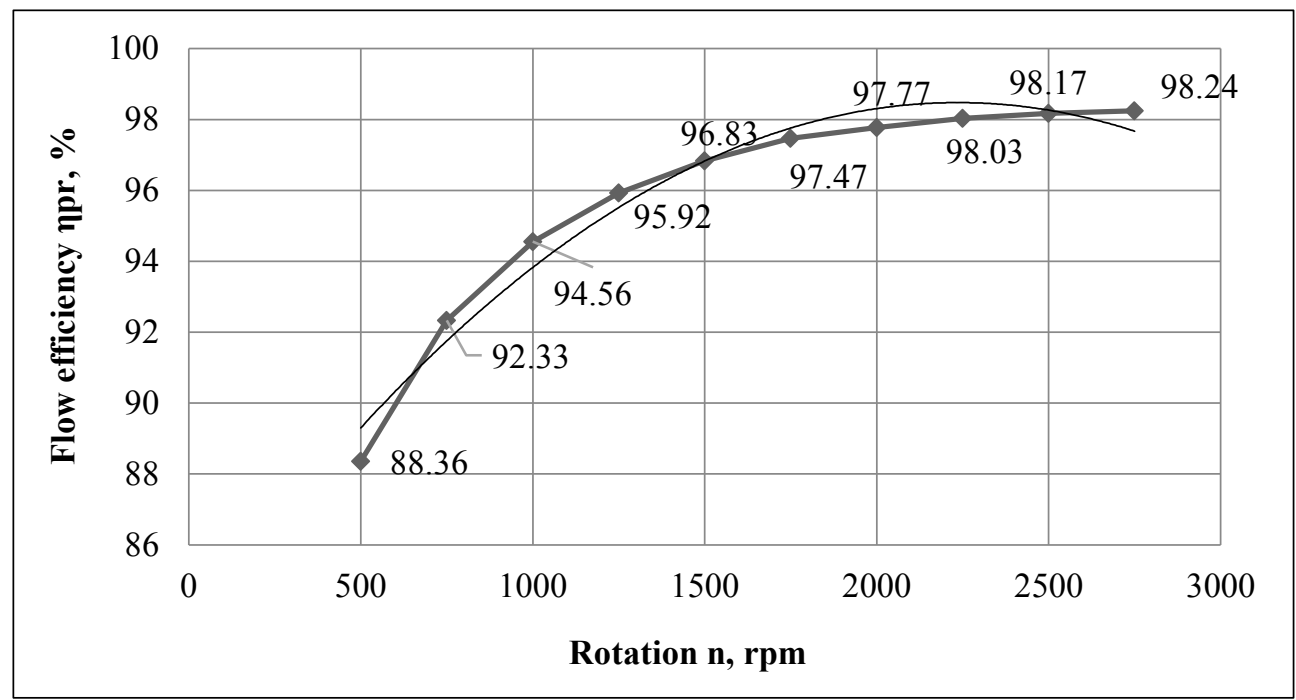

Fig. 3. Flow efficiency of the hydraulic pump at 0 hours 
Figure 3 shows the flow efficiency of the hydraulic pump at 0 hours. The flow efficiency at $500 \mathrm{rpm}$ reached $88.36 \%$ and at $2,750 \mathrm{rpm}$ reached $98.24 \%$. The largest increase in flow efficiency as a function of rotation is between $500 \mathrm{rpm}$ and $1500 \mathrm{rpm}(8.47 \%)$, after exceeding 1,500 rpm (nominal rotation) to $2750 \mathrm{rpm}$, there was an increase in flow efficiency (1.41\%). The given course of flow efficiency is caused by the remaining fluid in the tooth gaps. As the rotation increases, the centrifugal force acting on the fluid increases, reducing losses due to fluid remaining in the tooth gaps and thus increasing the flow efficiency itself. The influence of the centrifugal force on the fluid according to the mentioned authors is the greatest after the value of approx. 1,500 rpm, after reaching these rotations, the effect of the centrifugal force on the fluid has only a slightly increasing characteristic. The flow efficiency is also affected by the dynamic viscosity of the fluid, which even a centrifugal force can no longer overcome at high rotation.

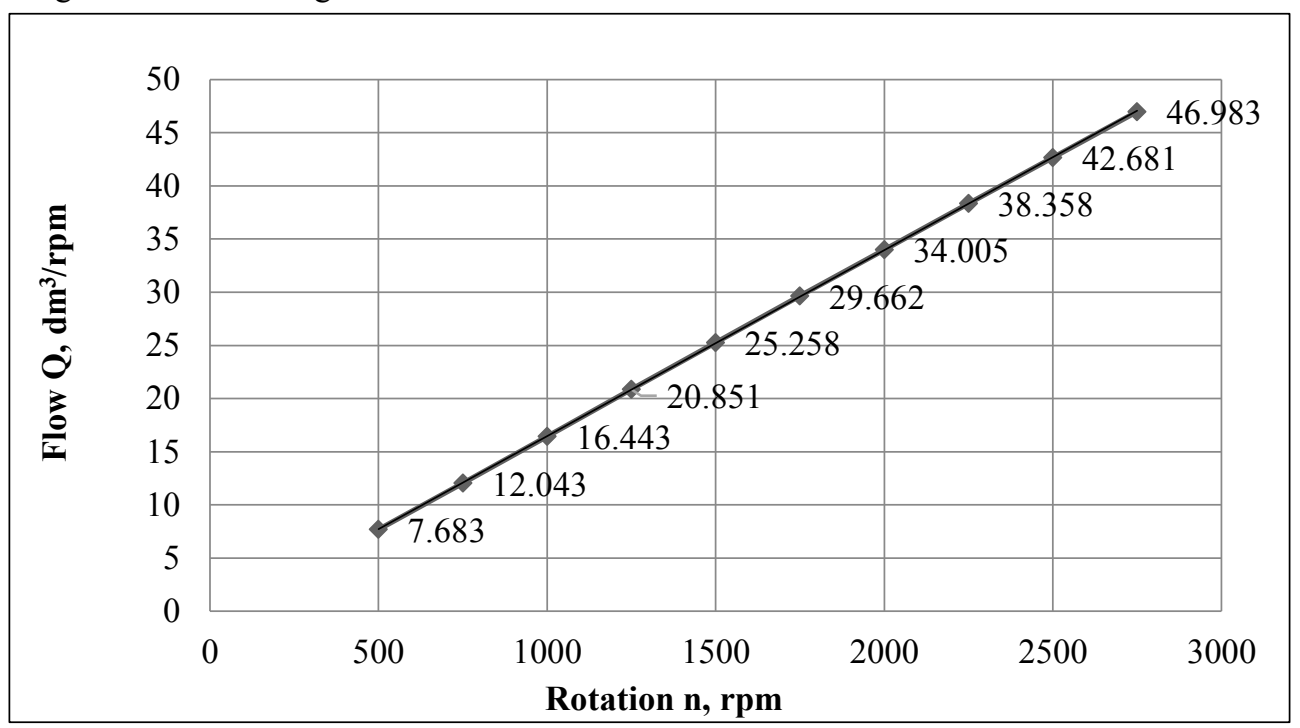

Fig. 4. Flow characteristic of the hydraulic pump at 0 hours

Figure 4 shows the flow characteristic of the hydraulic pump at 0 hours depending of the minimum rotation of $500 \mathrm{rpm}$ to $2,750 \mathrm{rpm}$. The flow characteristic at $500 \mathrm{rpm}$ reached 7.68 $\mathrm{dm}^{3} / \mathrm{rpm}$ and at $2,750 \mathrm{rpm}$ reached $46.98 \mathrm{dm}^{3} / \mathrm{rpm}$. The increase in flow characteristic depending of rotation is between $500 \mathrm{rpm}$ and $2,750 \mathrm{rpm}\left(39.3 \mathrm{dm}^{3} / \mathrm{rpm}\right)$, characteristic having an almost linear course. Table 5 shows the flow characteristics after 125 hours of operation with a statistical evaluation as a function of the minimum rotation of $500 \mathrm{rpm}$ after $2,750 \mathrm{rpm}$. 
Table 5. Basic statistical evaluation of flow characteristics of a hydraulic pump after 125 hours

\begin{tabular}{|c|c|c|c|c|c|c|c|c|c|}
\hline $\begin{array}{l}\text { Flow } \\
\text { Q at } \\
\text { rotati } \\
\text { on } n \text {, } \\
\text { rpm }\end{array}$ & $\begin{array}{c}\text { Ave } \\
\text { rage } \\
\frac{\mathscr{x}}{\overline{\mathbf{x}}}\end{array}$ & $\begin{array}{c}\text { Median } \\
\text {, Me }\end{array}$ & $\begin{array}{l}\text { Modu } \\
\text { s, Mo }\end{array}$ & $\begin{array}{c}\text { Min. } \\
\text { value, } \\
\mathbf{x}_{\text {min }}\end{array}$ & $\begin{array}{c}\text { Max. } \\
\text { value, } \\
\mathbf{x}_{\max }\end{array}$ & $\begin{array}{c}\text { Varianc } \\
\mathrm{e}, \sigma^{2}\end{array}$ & $\begin{array}{c}\text { Stand } \\
\text { ard } \\
\text { deviat } \\
\text { ion, } \\
\sigma\end{array}$ & $\begin{array}{c}\text { Coeff. } \\
\text { of } \\
\text { variatio } \\
\mathbf{n}, \\
\mathbf{V}_{\mathbf{k}}\end{array}$ & $\begin{array}{c}\text { Flo } \\
\text { w } \\
\text { effic } \\
\text { ienc } \\
y, \\
\%\end{array}$ \\
\hline 500 & $\begin{array}{c}7.74 \\
0\end{array}$ & 7.750 & 7.950 & 7.340 & 8.130 & 0.035 & 0.186 & 2.404 & $\begin{array}{c}89.0 \\
2\end{array}$ \\
\hline 750 & $\begin{array}{c}12.1 \\
32 \\
\end{array}$ & 12.160 & $\begin{array}{c}12.30 \\
0\end{array}$ & 11.690 & 12.560 & 0.045 & 0.212 & 1.750 & $\begin{array}{c}93.0 \\
2 \\
\end{array}$ \\
\hline 1000 & $\begin{array}{c}16.5 \\
07\end{array}$ & 16.520 & $\begin{array}{c}16.75 \\
0\end{array}$ & 16.020 & 16.950 & 0.056 & 0.236 & 1.433 & $\begin{array}{c}94.9 \\
2\end{array}$ \\
\hline 1250 & $\begin{array}{c}20.9 \\
19\end{array}$ & 20.930 & $\begin{array}{c}20.75 \\
0\end{array}$ & 20.410 & 21.460 & 0.064 & 0.252 & 1.205 & $\begin{array}{c}96.2 \\
3\end{array}$ \\
\hline 1500 & $\begin{array}{c}25.3 \\
14\end{array}$ & 25.320 & $\begin{array}{c}25.36 \\
0\end{array}$ & 24.780 & 25.830 & 0.069 & 0.263 & 1.039 & $\begin{array}{c}97.0 \\
4\end{array}$ \\
\hline 1750 & $\begin{array}{c}29.7 \\
33\end{array}$ & 29.730 & $\begin{array}{c}29.95 \\
0\end{array}$ & 29.210 & 30.360 & 0.073 & 0.271 & 0.910 & $\begin{array}{c}97.7 \\
0\end{array}$ \\
\hline 2000 & $\begin{array}{c}34.0 \\
88\end{array}$ & 34.080 & $\begin{array}{c}34.02 \\
0\end{array}$ & 33.580 & 34.610 & 0.072 & 0.268 & 0.785 & $\begin{array}{c}98.0 \\
1\end{array}$ \\
\hline 2250 & $\begin{array}{c}38.3 \\
39 \\
\end{array}$ & 38.350 & $\begin{array}{c}38.15 \\
0\end{array}$ & 37.790 & 38.910 & 0.070 & 0.265 & 0.692 & $\begin{array}{c}97.9 \\
8\end{array}$ \\
\hline 2500 & $\begin{array}{c}42.6 \\
62\end{array}$ & 42.660 & $\begin{array}{c}42.66 \\
0\end{array}$ & 42.140 & 43.180 & 0.070 & 0.264 & 0.619 & $\begin{array}{c}98.1 \\
3 \\
\end{array}$ \\
\hline 2750 & $\begin{array}{c}47.0 \\
39 \\
\end{array}$ & 47.030 & $\begin{array}{c}46.99 \\
0 \\
\end{array}$ & 46.550 & 47.510 & 0.060 & 0.245 & 0.521 & $\begin{array}{c}98.3 \\
6 \\
\end{array}$ \\
\hline
\end{tabular}

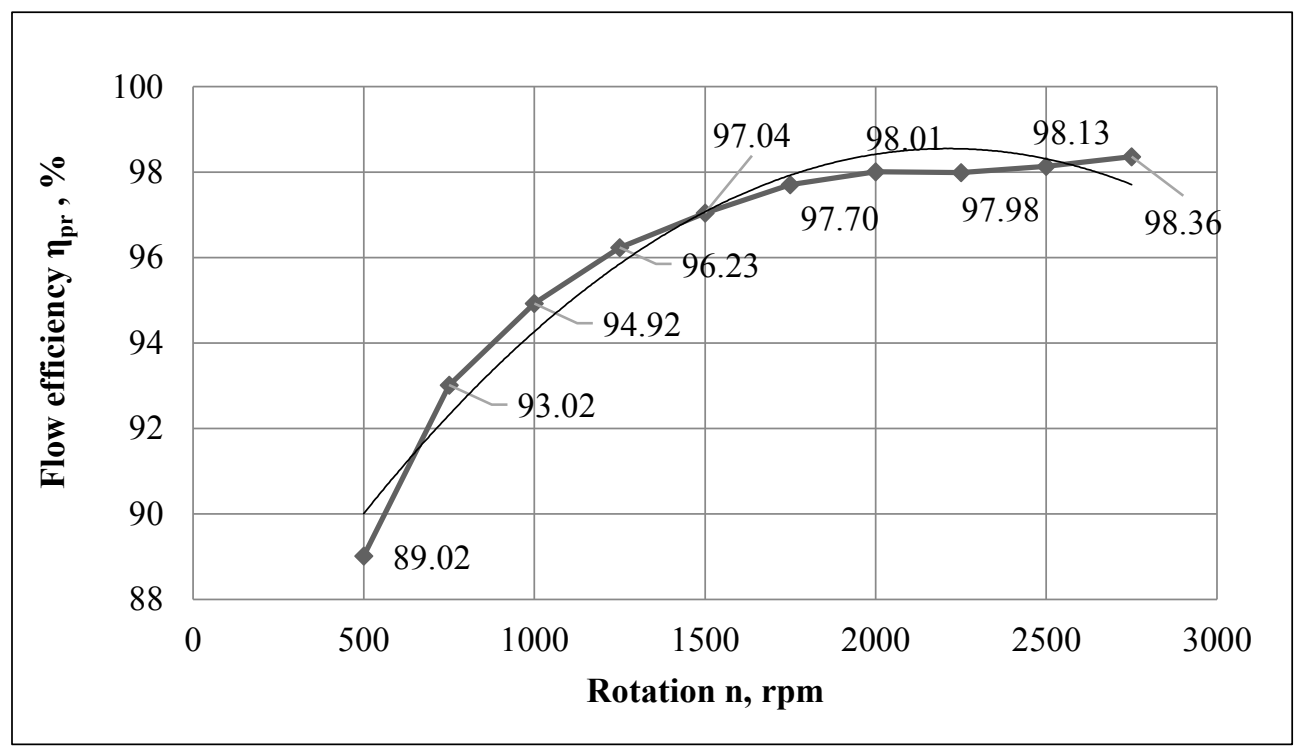

Fig. 5. Flow efficiency of the hydraulic pump after 125 hours 
Figure 5 shows the flow efficiency of the hydraulic pump after 125 hours, where the flow efficiency at $500 \mathrm{rpm}$ of $89.02 \%$ and at $2.750 \mathrm{rpm}$ reached $98.36 \%$. The largest increase in flow efficiency as a function of rotation is between $500 \mathrm{rpm}$ and 1,500 rpm (8.02\%), after exceeding the nominal rotation of $1,500 \mathrm{rpm}$ to $2,750 \mathrm{rpm}$ there was an increase in flow efficiency $(1.32 \%)$.

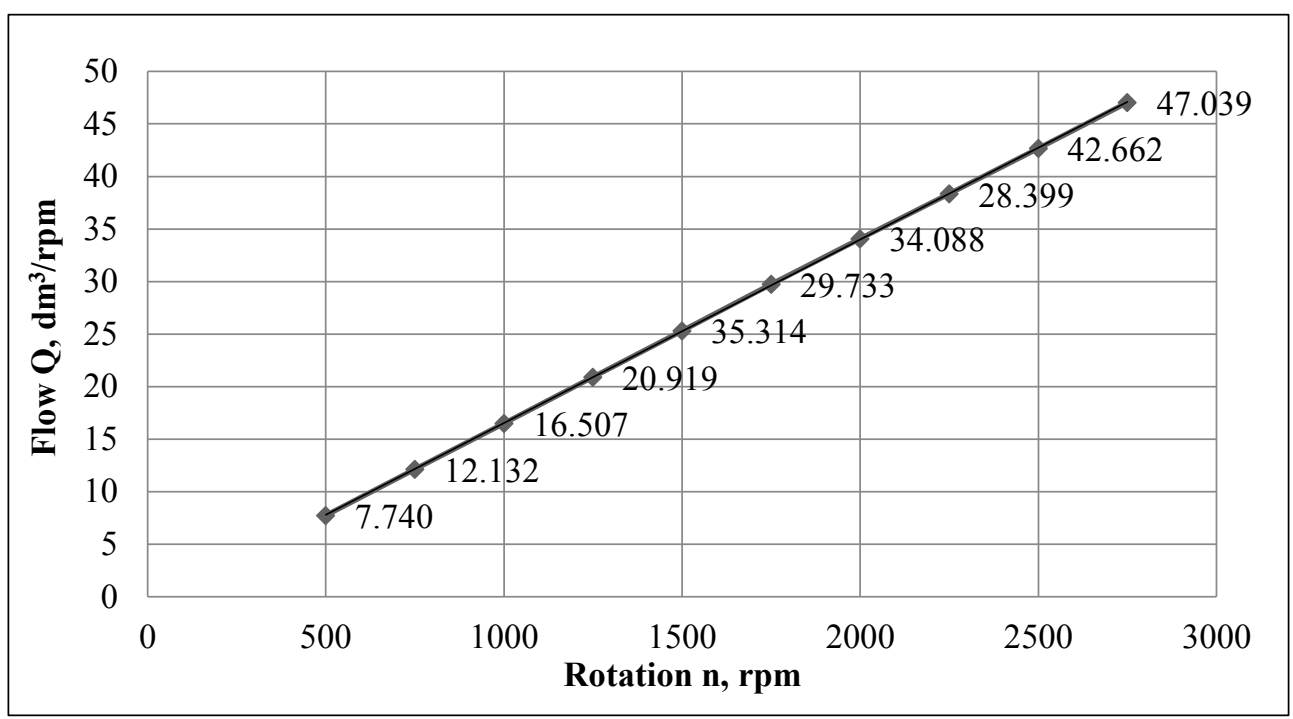

Fig. 6. Flow characteristic of the hydraulic pump after 125 hours worked

Figure 6 shows the flow characteristic of the hydraulic pump after 125 hours depending of a minimum rotation of $500 \mathrm{rpm}$ after $2,750 \mathrm{rpm}$. The flow characteristic reached a value of $7.74 \mathrm{dm}^{3} / \mathrm{rpm}$ at a rotation of $500 \mathrm{rpm}$ and reached a value of $47.04 \mathrm{dm}^{3} / \mathrm{rpm}$ at a rotation of $2,750 \mathrm{rpm}$. The increase in flow characteristic depending of rotation between $500 \mathrm{rpm}$ and $2,750 \mathrm{rpm}$ represents a value $39.3 \mathrm{dm}^{3} / \mathrm{rpm}$. The above characteristic has a linear course.

Author [12], dealt with hydraulic pumps and their flow efficiency in her research. In her work, was the maximum flow efficiency of the gear hydraulic pump at the level of $\eta=0.91$, while our measurement showed the flow efficiency at $\eta=0.9836$, after 125 hours. These differences in values could be due to several factors. In our opinion the main reason was the fact, that the author [12] used a different type of hydraulic fluid. Another author in his work states the efficiency of a hydraulic pump loaded with pressure at the level of $\eta=0.92$ [13]. The author [14], also dealt with similar measurements with hydraulic pumps in his article. By measuring, he found the flow efficiency of a rotary gear hydraulic pump at level $\eta=$ 0.9745 , which is similar to our found values. However, there is a need to emphasize that in his measurements was use a rotary gear hydraulic pump with external gearing.

\section{Conclusion}

The laboratory test equipment made it possible to simulate the variable test conditions to simulate the real conditions under which the hydraulic system of the agricultural tractor operates. The analysis of working fluids in has already been dealt with by the authors [15] and [1]. According to the author [8] it is important to monitor the outflow of hydraulic fluid to the hydraulic circuit. During the testing, the flow properties of the hydraulic pump with the tested hydraulic fluid were monitored at precisely determined intervals, where the flow efficiency of the hydraulic pump with biodegradable universal fluid at 0 hours worked 
reached $88.36 \%$, measured at $500 \mathrm{rpm}$ and at $2,750 \mathrm{rpm}$ reached $98.24 \%$. The largest increase in flow efficiency depending of rotation is in the range of $500 \mathrm{rpm}$ to $1,500 \mathrm{rpm}$ $(8.47 \%)$, after exceeding the rotation of $1,500 \mathrm{rpm}$ (nominal rotation) to the value of 2,750 $\mathrm{rpm}$, the flow efficiency increased by $1.41 \%$. The flow characteristic of the hydraulic pump at the biodegradable universal fluid at 0 hours worked reached $7.68 \mathrm{dm}^{3} / \mathrm{rpm}$ at $500 \mathrm{rpm}$ and at $2,750 \mathrm{rpm}$ reached $46.98 \mathrm{dm}^{3} / \mathrm{rpm}$. The increase in flow characteristic depending of rotation in the range of $500 \mathrm{rpm}$ to $2,750 \mathrm{rpm}$ is $39.3 \mathrm{dm}^{3} / \mathrm{rpm}$. The stated flow characteristics had an almost linear course in the form of the entire duration of the laboratory test. The stated flow characteristics of the hydraulic pump correspond to the measured result, during the verification measurement of the proposed laboratory test equipment for testing hydraulic pumps and transmission-hydraulic fluids. The evaluation of hydraulic fluids depending on the operating conditions was dealt with by the author [16]. It found that the operating parameters, temperature and pressure, influence the working fluid and subsequent measurements. Based on the processed set of measured data and the course of graphical dependence of average values of flow efficiency as a function of time worked, it can be concluded that the tested transmission-hydraulic fluid and its physical properties do not negatively affect the flow efficiency of hydraulic pump QHD 17 during 125 hours test.

This work was supported by project VEGA 1/0155/18 ,Applied research of the use of ecological energy carriers in agricultural, forestry and transport technology. “

This work was supported by project KEGA 028SPU-4/2019 „Practical utilization of design and testing knowledge of transmission systems of hydraulic mechanisms of mobile agricultural and forestry machinery."

This work was supported by project APVV SK-PL-18-0041 „The Development of Scientific Cooperation in the Study of the Effects of Biofuels in Road Transport, Including Environmental Impact."

\section{References}

1. Š. Čorňák, ERDev, 2048 (2018)

2. M. Rundo, Energies 10, 1261 (2017)

3. J. Tulík, J. Ksiba, J. Stančík, I. Štulajder, Acta technol. agric. 17, 24 (2014)

4. F. Tóth, A. Fürstenzeller, J. Rusnák, M. Bošanský, M. Kadnár, Acta technol. agric. 22, 134 (2019)

5. M. Puškár, T. Brestovič, N. Jasminská, Int. J. Veh. Des., 67, 63 (2015)

6. M. Košinár, I. Kuric, Adv. Sci. Technol., 6, 115 (2011)

7. I. Kuric, I. Zajačko, M. Cisár, Adv. Sci. Technol. Res. J., 10, 59 (2016)

8. M. Majdan, R. Abrahám, M. Kučera, M. Haas, Acta Univ. Agric. Silvic. Mendel. Brun. 64, 825 (2016)

9. J. Tulík, J. Kosiba, M. Szabó, F. Varga, P. Kangalov, J. Mareček, Agricultural, forest and transport machinery and technologies 2, 11 (2015)

10. M. Puškár, A. Jahnátek, I. Kuric, J. Kádárová, M. Kopas, M. Šoltésová, Air Qual. Atmos. Health , 12, 855 (2019)

11. M. Markiewicz-Patalon, L. Muślewski, J. Kaszkowiak, M. Sójka, IOP Conf Ser Mater Sci Eng 421, 1 (2018)

12. T. Minav, J. Heikkinen, M. Pietola, Electr. Power Syst. Res. 152, 390 (2017)

13. G. Ritzo, G. P. Massarotti, A. Bonanno, R. Paoluzzi, M. Raimondo, M. Blosi, F. Veronesi, A. Caldarellu, G. Guarini, J. Fluid Power 16, 1 (2015) 
14. J. Tulik, M. Halenár, P. Kuchar, M. Jánošová, Traktori i pogonske mašine 21, 64 (2016)

15. B. Kopiláková, J. Turza, L. Hujo, J. Kosiba, Tribology in Industry, 39, 129 (2017) 